\title{
Adsorption von Biomolekülen an planaren optischen Waveguides
}

\author{
Kurrat R., Textor M., Ramsden J.J. ${ }^{1}$, Spencer N.D., Böni P. \\ Laboratory for Surface Science and Technology, \\ Department of Materials, ETH Zürich, CH-8092 Zürich \\ ${ }^{1}$ Department of Biophysical Chemistry, \\ Biocenter of the University, $\mathrm{CH}-4056$ Basel \\ ${ }^{2}$ Paul Scherrer Institut, $\mathrm{CH}-5232$ Villigen PSI
}

\section{EINLEITUNG:}

Titan ist wegen seiner exzellenten Biokompatibilität ein weit verbreitetes Implantmaterial. In Kontakt mit der biologischen Umgebung adsorbieren an der Oberfläche Biomoleküle, z.B. Proteine, die das weitere Verhalten des Implantats im Körper entscheidend beeinflussen. Daher ist es wichtig, die entsprechenden Oberflächenprozesse genau zu kennen [1].

Die Methode der 'Optical Waveguide Lightmode Spectroscopy' (OWLS) ist für kinetische Untersuchungen von Adsorptionsprozessen an Oberflächen von Waveguides sehr geeignet, z.B. Adsorption von Proteinen [2,3] oder Zellen [4]. Um möglichst gezielt die Oberflächeneigenschaften von Titanimplantaten nachzustellen, wurden die Waveguide Oberflächen mit Titanoxid (TiO2) mittels PVD (thermische Verdampfung) und Magnetron Sputtering beschichtet.

\section{METHODE:}

Die OWLS Methode basiert auf dem Prinzip der Totalreflexion von Licht in Medien mit hohem Brechungsindex [5]. Figur 1 zeigt den schematischen Aufbau der Apparatur:

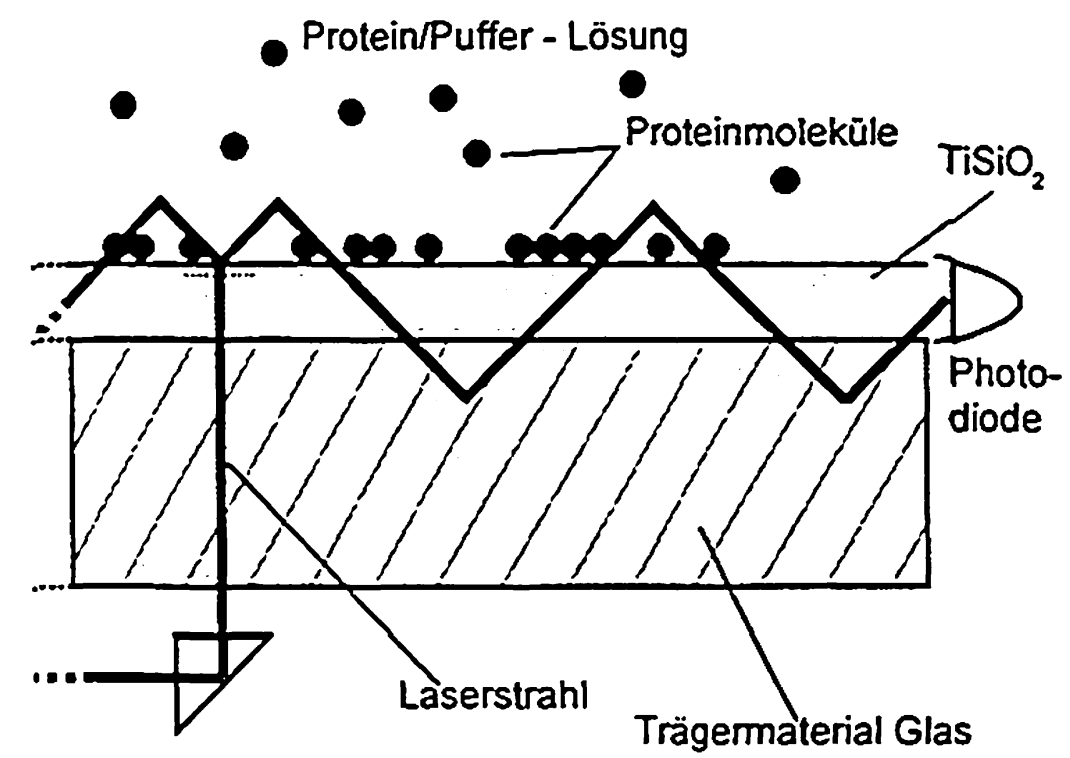

Figur 1: Schematische Darstellung des OWLS Prinzips.

Der von unten kommende Laserstrahl wird dabei mit Hilfe eines Beugungsgitters in die hochbrechende Schicht (Mischung aus $\mathrm{SiO}_{2}$ und $\mathrm{TiO}_{2}$ ) eingekoppelt und durch Totalreflexion bis zum Ende des Waveguides geführt, wo er anschließend von Photodioden aufgefangen wird. Die geführte Welle dringt dabei in einem Bereich von ca. $100 \mathrm{~nm}$ in die Flüssigphase der Adsorptionszelle ein (evanessent wave) und tritt dabei in Wechselwirkung mit den an der Oberfläche befindlichen Molekülen (z.B. Proteine oder Zellen). In sehr dünnen Schichten (hier 150 bis $180 \mathrm{~nm}$ ) kann das Licht nur in diskreten Moden geführt werden. Um den effektiven Brechungsindex nach Gleichung (1) zu bestimmen wird daher der Winkel $\alpha$, mit dem der Laserstrahl auf das Beugungsgitter trifft, variiert.

$$
\begin{aligned}
& \qquad=n_{\text {air }} \cdot \sin \alpha+\frac{l \cdot \lambda}{\Lambda} \\
& l=\text { Beugungsordnung } \\
& \lambda=\text { Wellenlănge Laser }=632.816 \mathrm{~nm} \\
& \Lambda=\text { Gitterperiode }=416.15 \mathrm{~nm}
\end{aligned}
$$

Daraus läßt sich dann anschließend die Masse der adsorbierten Proteine berechnen [6,7].

\section{ARBEITEN und ERGEBNISSE:}

Die Messungen wurden an einem kommerziellen Instrument der Firma Artificial Sensing Instruments (ASI, Zürich) durchgeführt. Da die von diesem Gerät verwendeten Waveguides zu groß für ergänzende Untersuchungen mittels XPS, ToF-SIMS oder AFM sind, mußte zunächst eine Halterung für kleinere Waveguides hergestellt werden. Diese besteht aus einem Einsatz, welcher die Verbindung zu den Photodioden mittels zweier Lichtleiter Bündel aufrecht erhält. Dank der kleinen $(8 \times 12 \mathrm{~mm})$ Waveguides können nun z.B. XPS Messungen vor und nach einem OWLS Versuch gemacht werden. Dabei zeigte sich, das die verwendete Silicon Fließzelle eine hohe Kontamination der Waveguide Oberfläche zur Folge hatte. Abhilfe konnte hier durch die Verwendung einer Fließzelle aus $\mathrm{Kalrez}^{\circledR}$ (Dupond) geschaffen werden.

Titan Implantate besitzen auf ihrer Oberfläche immer eine natürliche Oxidschicht. Um nun die Oberfläche von Titan Implantaten möglichst gut zu simulieren, wurden die Waveguides mit einer zusätzlichen $\mathrm{TiO}_{2}$ Schicht versehen. Durch den hohen Brechungsindex des $\mathrm{TiO}_{2}$ werden dabei die Einkopplungswinkel zu größeren Winkeln verschoben; $a b$ einer gewissen Schichtdicke liegen sie außerhalb des verfügbaren Meßbereichs (Figur 2). Eine Beschichtungsdicke von $10 \mathrm{~nm}$ erwies sich als genügend dünn bzgl. Meßbereich und gleichzeitig genügend dick bzgl. Ausbildung einer geschlossenen Oberflächenschicht. 
Fig. 3 und 4 zeigen XPS Spektra der Waveguide Oberfläche vor und nach der $\mathrm{TiO}_{2}$ Beschichtung. Das völlige Verschwinden der Silizium Peaks zeigt, das die Schicht das Substrat vollständig bedeckt.

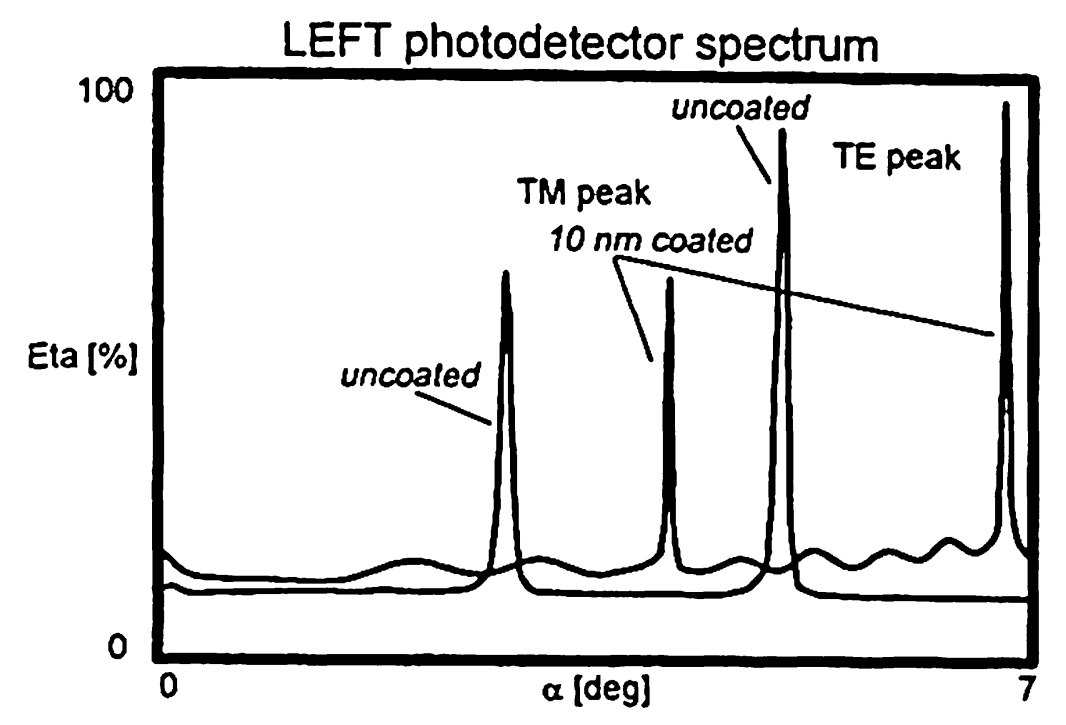

Figur 2: Gemessene Einkopplungswinkel mit und ohne zusätzlicher $\mathrm{TiO}_{2}$ Beschichtung.

XPS uncoated waveguide

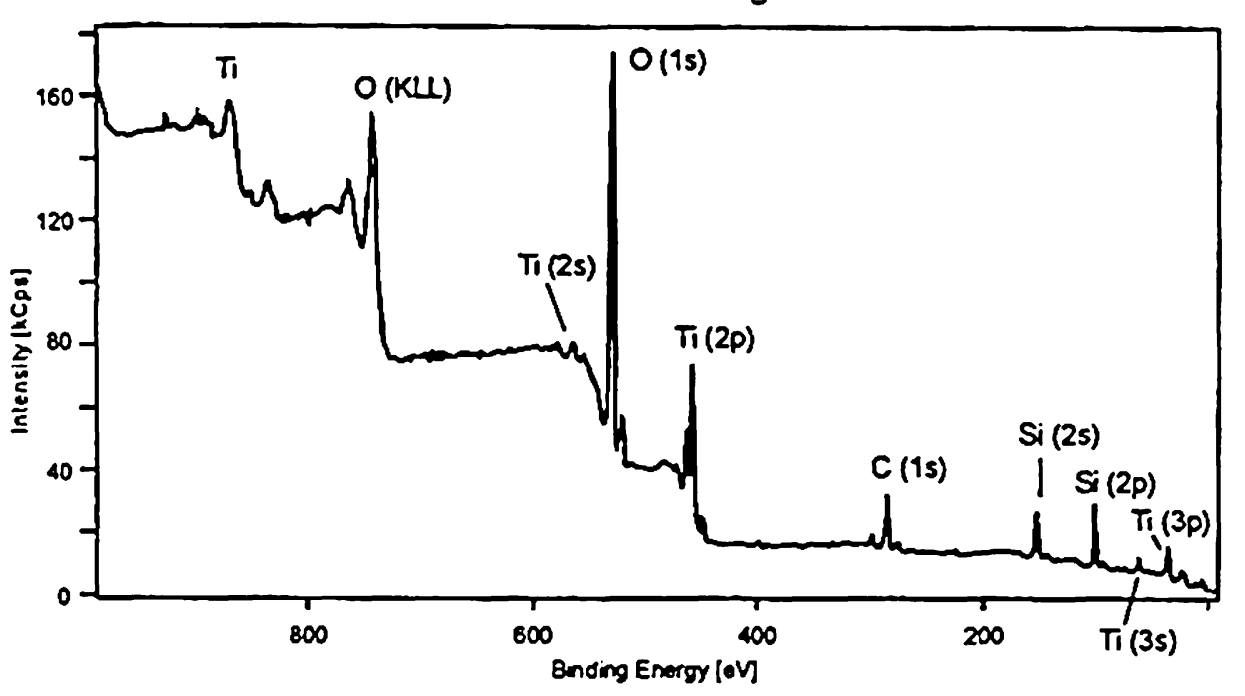

Figur 2: XPS Spektrum - unbeschichteter Waveguide. XPS ASI1400 with 10nm TIO2 coating

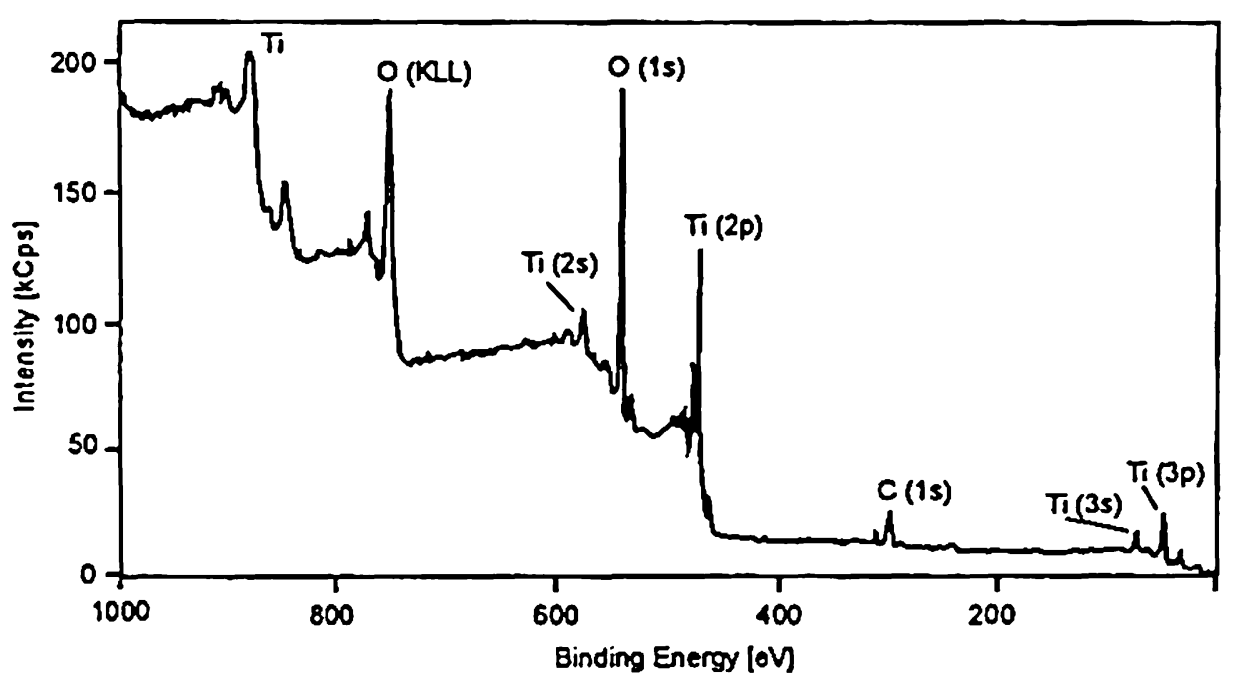

Figur 3: XPS Spektrum - mit $10 \mathrm{~nm} \mathrm{TiO}_{2}$ Beschichtung.

Für die Adsorptionsexperimente wird die Durchflußzelle mit der zu untersuchenden Lösung (z.B. Proteine in Pufferlösung) beschickt. Das Gerät liefert als Ergebnis den Verlauf der adsorbierten Masse mit einer Zeitauflösung von typisch $3 \mathrm{~s}$. Die Nachweisgrenze liegt bei ca. 1 $\mathrm{ng} / \mathrm{cm}^{2}$.

Figur 4 zeigt als Beispiel die Adsorption von Human Serum Albumin (HSA) auf einem $\mathrm{TiO}_{2}$ beschichteten Waveguide. Nach der anfänglichen Spülphase mit reinem Puffer (Konditionienung), folgt die Adsorption aus der Protein/Puffer Lösung. Anschließend wird ein Teil des Proteins beim zweiten Spülvorgang wieder von der Oberfläche entfernt. Dies deutet darauf hin, das es zwei verschiedene Adsorptionszustände des Proteins gibt: ein reversibler und ein irreversibler. In Fig. 4 sind neben den experimentellen Daten auch die Ergebnisse der kinetischen Modellierung auf Basis eines Adsorptionsmodells mit reversibler und irreversibler Komponente dargestellt.

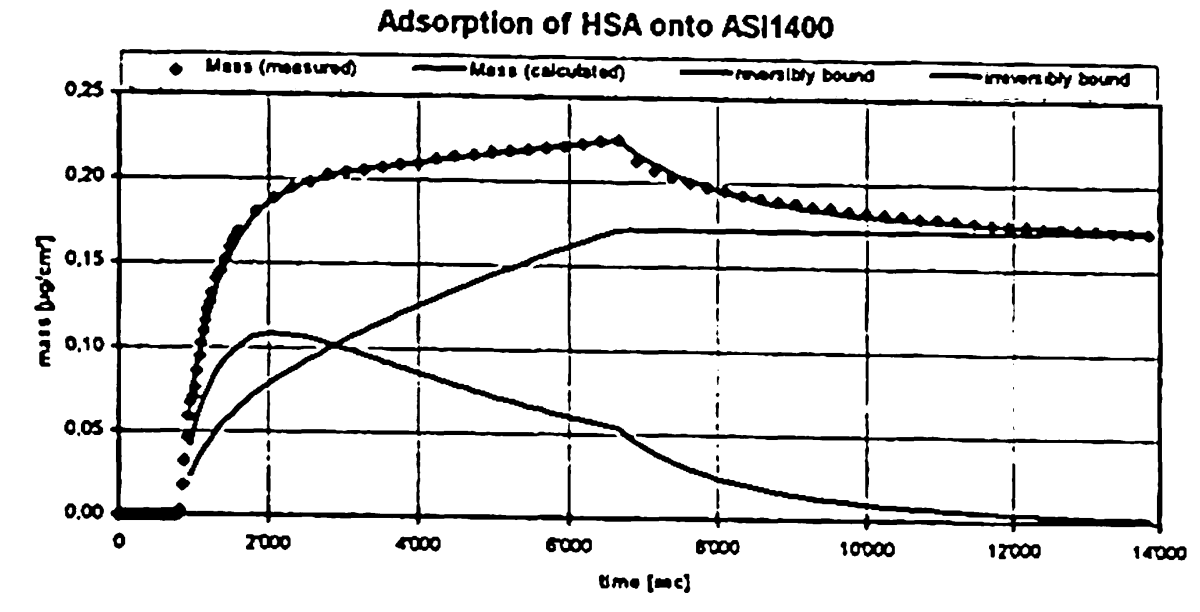

Figur 4: Human Serum Albumin auf $\mathrm{TiO}_{2}$ Waveguide

Die Summenkurve der beiden Zustände beschreibt dabei die experimentellen Daten sehr gut [3].

Weiterhin ist es mit gewissen Einschränkungen auch möglich, Zell-Adhäsion und -Ausbreitung (Spreading) zu messen. Da die Dimensionen der Zellen weit über den Meßbereich hinausgehen wird nur der grenzflächennahe Teil der adsorbierten Zelle erfaßt. Unter der Annahme das in einer ersten Phase keinerlei Ausbreitung der Zellen stattfindet, kann die Anzahl der angelagerten Zellen bestimmt werden. Sofern in der zweiten Phase keine weiteren Zellen hinzu kommen (gestoppter Fluß) kann die Ausbreitung der Zellen auf der Oberfläche durch den Anstieg des Signals verfolgt werden.

Derzeit im Gange ist ein Vergleich von OWLS mit der Quarz Crystal Microbalance (QCM) und mit in situ Ellipsometrie, um detaillierte Aussagen über die Genauigkeit und Nachweisempfindlichkeit der Methoden machen zu können.

\section{SCHLUSSFOLGERUNGEN:}

Die Optical Waveguide Lightmode Spectroscopy (OWLS) ist ein geeignetes Instrument für die Bestimmung der Adsorptionskinetik von Biomolekülen an Oberflächen mit hoher Empfindlichkeit und Zeitauflösung. Durch Beschichtung der Waveguide Oberfläche mit sehr dünnen Schichten kann der Einfluß der Oberflächenchemie studiert werden. Mittels $10 \mathrm{~nm} \mathrm{TiO}_{2}$ Sputterschichten lassen sich z.B. die Oberflächen von Titanimplantaten simulieren.

\section{LITERATUR:}

[1] B.D.Ratner, 1993, J. Biomed. Mat. Res., 27, 837

[2] J.J.Ramsden, 1993, Phys. Rev. Lett., 71, 295

[3] R.Kurrat, J.J.Ramsden, J.E.Prenosil, 1994, J. Chem. Soc.: Faraday Transactions, 90 4, 587

[4] J.J.Ramsden, S.Y.Li, E.Heinzle, J.E.Prenosil, 1995, Cytometry, 19 2, 97

[5] J.J.Ramsden, 1993, J. Stat. Phys., 73 5/6, 583

[6] W.Lukosz, K.Tiefenthaler, 1983, Opt. Lett. , 8, 537

[7] K.Tiefenthaler, W.Lukosz, 1989, J. Opt. Soc. Am. B, 6,209 